\title{
EFEITO DA TEMPERATURA NA SÍNTESE DE FERTILIZANTES DO TIPO TERMOPOTÁSSIO
}

\author{
A. A. S. SILVA ${ }^{1,2^{*}}$, M. E. MEDEIROS', J. A. SAMPAIO ${ }^{2}$ e F. M. S. GARRIDO ${ }^{1}$ \\ ${ }^{1}$ Universidade Federal do Rio de Janeiro \\ ${ }^{2}$ Centro de Tecnologia Mineral \\ adriana_soleiro@hotmail.com*
}

Artigo submetido em dezembro/2013 e aceito em dezembro/2015

DOI: $10.15628 /$ holos.2016.1874

\section{REAUMO}

No Brasil, o uso de fertilizantes intensificou-se com o propósito de aumentar a sua produtivida de agrícola. Uma consequência disso é o aumento nas importações de fertilizantes, uma vez que, a produção interna tornou-se insatisfatória. Baseado neste cenário é importante o desenvolvimento de fontes alternativas de sais de potássio para aplicação na agricultura como fertilizantes potássicos. Neste trabalho, propõe-se o desenvolvimento de fertilizantes termopotássicos, tomando-se como ponto de partida o verdete de Cedro do Aba eté. A rocha foi caracterizada pelas técnicas de espectroscopia vibracional na região do infravermel ho (IV), fluorescência de raios $X(F R X)$ e difração de raios $X(D R X)$. A presença da glauconita foi confirmada por DRX, pela análise de picos característicos em 10; 4,5; 2,4 e 1,5 Å, e por IV pelas bandas em 3520, 3440, 1020 e $630 \mathrm{~cm}^{-1}$. O teor de $\mathrm{K}_{2} \mathrm{O}$ (7\%) na rocha foi determinado por FRX. Esse teor advém dos minerais de potássio que constituem a rocha, sendo o principal deles a glauconita. Dos $7 \%$ em massa de $\mathrm{K}_{2} \mathrm{O}$, que constituem o verdete, somente $0,4 \%$, do $\mathrm{K}$ total, se encontram na forma solúvel. Visando a aumentar esse percentual calcinou-se a rocha a $800,1.000$ e $1.200^{\circ} \mathrm{Ce}$ a solubilidade do nutriente passou a 2,$5 ; 0,5$ e $0,06 \%$, do $\mathrm{K}$ total, respectivamente.

PALAVRAS-CHAVE: fertilizantes, potássio, glauconita, verdete.

\section{EFFECT OF TEMPERATURE ON THE SYNTHESIS OF A THERMOPOTASSIUM FERTILIZER}

\begin{abstract}
In Brazil, the use of fertilizers has been intensified in order to increasing agricultural productivity. One consequence is an increase in the import of fertilizers since, domestic production has become unsatisfactory. Based on this scenario this is important to develop alternative sources of potassium salts to be used in agricul ture as a potassium fertilizer. The purpose of this work is to develop thermopotassium fertilizers using as raw material a Brazilian called verdete from Cedro do Abaeté. The rock has been characterized by infrared spectroscopy (IR), $X$ ray fluorescence (XRF) e X-ray diffraction (XRD). The existence of glauconite was confirmed by XRD analysis of
\end{abstract}

the characteristic peaks at $10,4.5,2.4$ and $1.5 \AA$ and by IR bands at $3.520,3.440,1.020$ and $630 \mathrm{~cm}^{-1}$. This content comes from potassium minerals in the rock and the main one being the glauconite. This amount of potassium is related to the presence of potassium minerals in the rock and the main mineral is glauconite. Considering the quantity of potassium in the rock, only $0.4 \%$ of the total a mount of this nutrient is soluble. In order to increase this percentage the rock was roasted at $800,1.000$ and $1.200^{\circ} \mathrm{C}$ and the potassium solubility increased to $2.5,0.5$ and $0.06 \%$, respectively.

KEYWORDS: fertilizers; potassium; glauconite; verdete. 


\section{INTRODUÇÃO}

O uso de fertilizantes no Brasil intensificou-se com o propósito de aumentar a nossa produtividade agrícola. Como consequência, percebe-se um aumento no déficit da balança comercial do setor de minerais devido às volumosas importações de fertilizantes, uma vez que, a produção interna é insatisfatória (SILVA, 2009). Com relação aos fertilizantes potássicos, o problema é ainda mais grave. No Brasil existe apenas uma mina produtora de sal de potássio em operação, a de Taquari Vassouras, em Sergipe (SILVA et al., 2012a). Esta unidade produziu, de acordo com o Sumário Mineral Brasileiro de 2014 (OLIVEIRA, 2014), aproximadamente 492 mil toneladas de $\mathrm{KCl}$ em 2013, o que corresponde a apenas $6 \%$ das necessidades do país. Sendo assim, é de extrema importância realizar a busca e o desenvolvimento de fontes alternativas de sais de potássio para aplicação na agricultura como fertilizantes potássicos (DUARTE et al., 2013; MANCUSO et al., 2014; PESSOA et al., 2015; TEIXEIRA et al., 2011; 2012a; 2015a).

A utilização de rochas como nutriente agrícola pode contribuir para reduzir o consumo de fertilizantes industriais, os quais demandam demasiada quantidade de energia para sua produção e transporte (TEIXEIRA et al., 2012b). Deste modo, o desenvolvimento de um novo insumo agrícola, derivado de uma rocha existente no território nacional, beneficiaria o setor agrícola e mineral brasileiro (MARTINS et al., 2015; SANTOS et al., 2015; TEIXEIRA et al., 2015b). Dentre estas, o verdete de Cedro do Abaeté, município que está situado na bacia do Rio São Francisco, no estado de Minas Gerais (Brasil), a $285 \mathrm{~km}$ de Belo Horizonte, se destaca pelo teor de $\mathrm{K}_{2} \mathrm{O}$ que varia entre 6 e 14\% (SILVA et al., 2011), cuja coloração verde se deve à existência de íons $\mathrm{Fe}^{2+}$ na estrutura da glauconita, que é seu principal constituinte (SILVA e LANA, 2015; TOLEDO PIZA et al., 2011).

A glauconita, mineral de fórmula molecular $\mathrm{K}_{2}(\mathrm{MgFe})_{2} \mathrm{Al}_{6}\left(\mathrm{Si}_{4} \mathrm{O}_{10}\right)_{8}(\mathrm{OH})_{12}$, é um aluminossilicato lamelar hidratado de ferro e magnésio, cujo termo provém do grego "glaucos" que significa verde azulado (DANA, 1978). As lamelas do mineral são compostas por três folhas (duas tetraédricas e uma octaédrica), estas lamelas são empilhadas para a formação de uma estrutura cristalina lamelar que apresenta cátions interlamelares. Nas folhas octaédricas há a substituição isomórfica de mais da metade dos íons $\mathrm{Al}^{3+}$ por $\mathrm{Fe}^{2+}$ (SRASRA e TRABELSI-AYEDI, 2000; CHESHIRE e BISH, 2012) conforme indicado na Figura 1. Na glauconita, o cátion interlamelar predominante é o $\mathrm{K}^{+}$, podendo haver também os íons $\mathrm{Na}^{+}$e $\mathrm{Ca}^{2+}$ (KOSTER, 1977).

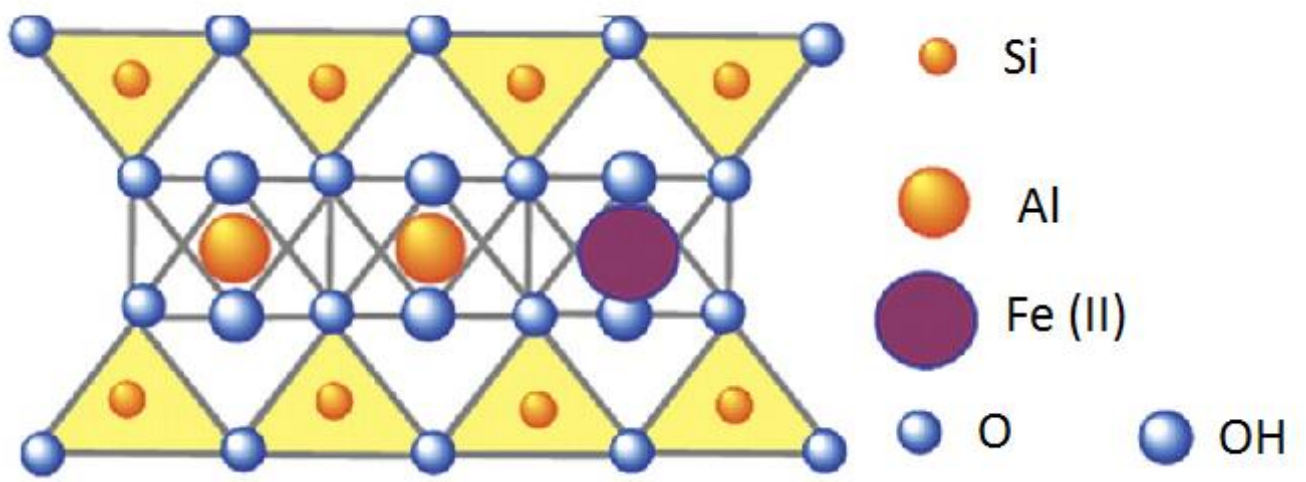

Figura 1: Representação da estrutura da lamela da glauconita (Adaptado de CHESHIRE e BISH, 2012). 
Neste trabalho, propõe-se o desenvolvimento de fertilizantes termopotássicos, tomandose como ponto de partida o verdete de Cedro do Abaeté. Fertilizantes termopotássicos sãoaqueles resultantes do tratamento térmico de rochas potássicas, com ou sem adição de outros tipos de rocha. O tratamento térmico tem por fim destruir a estrutura cristalina dos minerais, fonte de potássio, permitindo assim a formação de materiais nos quais este nutriente se encontre numa forma mais disponível para as plantas (SILVA et al., 2012a). Os fertilizantes termopotássicos caracterizam-se por sua insolubilidade em água, entretanto, estes são solúveis em ácido cítrico e solução de citrato de amônio (VALLARELI et al., 1993). Neste contexto, o objetivo deste trabalho foi o de investigar o efeito do tratamento térmico, do verdete de Cedro do Abaeté, na quantidade de potássio solúvel, quantificado por meio de extrações em solução de ácido cítrico.

\section{MATERIAIS E MÉTODOS}

\subsection{PREPARAÇÃO da amostra}

A amostra de verdete de Cedro do Abaeté foi cominuída com auxílio de um britador de mandíbulas conforme descrito por SILVA et al. (2012b). O material britado foi rebritado em um britador de rolos, operando em circuito fechado com uma peneira de 2,38 mm (SILVA et al., 2012b). Na etapa seguinte o material foi homogeneizado em pilha prismática de $10 \mathrm{~m}$ de comprimento, utilizando as facilidades da usina piloto do CETEM. De início, procedeu-se a distribuição da amostra em pilha de homogeneização, da qual foram retiradas amostras de $20 \mathrm{~kg}$. $\mathrm{Na}$ etapa seguinte as amostras foram quarteadas com o auxílio de um quarteador tipo Jones para a coleta de alíquotas de $1,0 \mathrm{~kg}$, que foram utilizadas neste estudo.

\subsection{CARACTERIZAÇÃO}

Para a realização desta etapa as amostras foram cominuídas até a granulometria abaixo de $0,15 \mathrm{~mm}$ e submetidas às técnicas de fluorescência de raios $X(F R X)$, difração de raios $X(D R X)$ e espectroscopia no infravermelho (IV).

A composição química do verdete de Cedro do Abaeté foi determinada pela técnica de FRX. A identificação das fases mineralógicas foi realizada pela técnica de difração de raios $X$, no equipamento DRX Bruker-D4 Endeavor, com passo do goniômetro de $0,02^{\circ}$ em $2 \theta$, com 1,0 s de tempo de contagem e radiação Co-k $\alpha$ ( $\lambda=1,789 \dot{A} ; 35 \mathrm{kV} / 40 \mathrm{~mA})$, na faixa angular (20) variando de $5^{\circ}$ a $40^{\circ}$, sendo interpretados qualitativamente pela comparação com os padrões contidos no banco de dados do ICSD Web - Periódicos CAPES.

As análises de espectrometria no infravermelho foram realizadas em um equipamento Magna 760, da marca Nicolet, com número de onda variando de 4.000 a $400 \mathrm{~cm}^{-1}$ e resolução de $4 \mathrm{~cm}^{-1}$. Os espectros foram obtidos por meio de discos (pastilha) de $\mathrm{KBr}$ anidro. As atribuições das bandas observadas no espectro de infravermelho foram realizadas por tentativa.

\subsection{TRATAMENTO TÉRMICO}

Para os ensaios de tratamento térmico, dez gramas de verdete de Cedro do Abaeté foram pesados em cadinho de porcelana e calcinados a $800,1.000$ e $1.200^{\circ} \mathrm{C}$ por duas horas em forno estático. Após a calcinação, o material foi submetido a um choque térmico em água a temperatura 
ambiente. O material final foi retirado do cadinho, macerado com o auxílio de gral e pistilo, sendo peneirado abaixo de $0,15 \mathrm{~mm}$. Os materiais obtidos, após tratamento térmico, foram caracterizados por DRX e IV.

\subsection{QUANTIFICAÇÃO DE POTÁSSIO SOLÚVEL}

Ao final do tratamento térmico, $5 \mathrm{~g}$ do material calcinado foram adicionados a um erlenmeyer que continha $50 \mathrm{~mL}$ de solução de ácido cítrico $1 \mathrm{~mol} / \mathrm{L}$. O erlenmeyer permaneceu por um período de $4 \mathrm{~h}$ em uma mesa agitadora. Após as $4 \mathrm{~h}$ de agitação, a solução foi filtra da e enviada para análise química por absorção atômica para a determinação do teor de potássio solúvel no material calcinado.

\section{RESULTADOS E DISCUSSÃO}

\subsection{CARACTERIZAÇÃO}

A composição química do verdete de Cedro do Abaeté foi determinada pela técnica de FRX. Foi possível determinar, pela análise dos resultados obtidos, que os principais constituintes da amostra são silício, alumínio, potássio, ferro e magnésio. Os teores dos óxidos de elemento estão relacionados na Tabela 1.

Tabela 1 - Percentual em massa dos principais constituintes do verdete de Cedro do Abaeté.

\begin{tabular}{c|c}
\hline ÓXIDO & MASSA (\%) \\
\hline $\mathrm{SiO}_{2}$ & 64,7 \\
\hline $\mathrm{Al}_{2} \mathrm{O}_{3}$ & 13,5 \\
\hline $\mathrm{K}_{2} \mathrm{O}$ & 7,0 \\
\hline $\mathrm{Fe}_{2} \mathrm{O}_{3}$ & 5,7 \\
\hline $\mathrm{MgO}$ & 2,0 \\
\hline
\end{tabular}

Os resultados obtidos por FRX estão de acordo com aqueles resultantes da técnica de DRX. Os principais minerais que constituem a rocha foram determinados por DRX e identificados como quartzo $\left(\mathrm{SiO}_{2}\right)$, glauconita $\left(\mathrm{K}_{2}(\mathrm{MgFe})_{2} \mathrm{Al}_{6}\left(\mathrm{Si}_{4} \mathrm{O}_{10}\right)_{3}(\mathrm{OH})_{12}\right)$, ilita $\left(\mathrm{KAl}_{2}\left[(\mathrm{SiAl})_{4} \mathrm{O}_{10}\right][\mathrm{OH}]_{2}\right)$ e clorita serpentina $\left((\mathrm{MgAl})_{6}(\mathrm{SiAl})_{4} \mathrm{O}_{10}(\mathrm{OH})_{8}\right)$. A glauconita foi identificada como o principal mineral potássico constituinte da amostra pela existência de picos característicos em 2 Theta $=10,1 ; 22,8$ e 40,4 graus (SRASRA e TRABELSI-AYEDI, 2000).

A ocorrência desse mineral como principal constituinte da amostra foi confirmada pela análise das bandas observadas no espectro de infravermelho. Foi possível observar bandas características da glauconita, relativas ao estiramento da ligação $\mathrm{OH}$, em 3.614, 3.557, 3.533 e $3.417 \mathrm{~cm}^{-1}$ (OSPITALI et al., 2008). A estrutura do silicato foi caracterizada pela ocorrência de uma banda em torno de $1.013 \mathrm{~cm}^{-1}$ que é atribuída aos modos de vibração de estiramento das ligações $\mathrm{Si}-\mathrm{O}-\mathrm{Si}$. Algumas bandas relativas aos modos de deformação referentes às ligações Si-O-Fe e Si-O em $518 \mathrm{~cm}^{-1}$ e $468 \mathrm{~cm}^{-1}$ também foram observadas.

\subsection{Tratamento térmico e quantificação de potássio solúvel}

O percentual de potássio contido na rocha ( $\mathrm{K}$ total) é de aproximadamente $7 \%$ (Tabela 1 ), ou seja, o verdete de Cedro do Abaeté contém $7 \mathrm{~g}$ de potássio para cada $100 \mathrm{~g}$ de rocha. No 
entanto, somente uma parcela do potássio total está disponível para troca iônica. Nesse trabalho, a quantidade de potássio disponível para troca iônica é chamado de potássio solúvel.

O potássio solúvel contido na amostra de verdete de Cedro do Abaeté in natura, ou seja, sem nenhum tipo de tratamento, foi quantificado por extração em solução de ácido cítrico $1 \mathrm{~mol} / \mathrm{L}$. Determinou-se que somente $0,4 \%$ do potássio total contido na rocha $(0,028$ g a cada $100 \mathrm{~g}$ de rocha) estão na forma solúvel. Dessa forma, ensaios de calcinação do verdete foram realizados, a $800,1.000$ e 1200 com o propósito de aumentar a solubilidade do nutriente, e os resultados estão relacionados na Tabela 2.

Tabela 2 - Percentual de potássio solúvel em solução de ácido cítrico $1 \mathrm{~mol} / \mathrm{L}$.

\begin{tabular}{c|c}
\hline AMOSTRA & K SOLÚVEL (\% DO K TOTAL) \\
\hline VERDETE IN NATURA & 0,4 \\
\hline VERDETE CALCINADO A $800^{\circ} \mathrm{C}$ & 2,5 \\
\hline VERDETE CALCINADO A $1000^{\circ} \mathrm{C}$ & 0,5 \\
\hline VERDETE CALCINADO A $1200^{\circ} \mathrm{C}$ & 0,06 \\
\hline
\end{tabular}

Pela análise dos resultados (Tabela 2) percebe-se que quando o verdete é calcinadoa $800^{\circ} \mathrm{C}$ o percentual de potássio solúvel na rocha aumenta de 0,4 para $2,5 \%$. No entanto, quando a rocha é calcinada a 1.000 e $1.200^{\circ} \mathrm{C}$ o percentual solúvel do nutriente diminui para 0,5 e $0,06 \%$, respectivamente. Esses resultados podem ser explicados pelas modificações estruturais sofridas por seus minerais constituintes. Sendo que, as técnicas de caracterização utilizadas, discutidas a seguir, foram capazes de evidenciar tais transformações.

Os espectros obtidos na região do infravermelho são apresentados na Figura 2. Para a amostra original in natura (Figura 2a), observam-se as bandas características da glauconita, relativas ao estiramento da ligação $\mathrm{O}-\mathrm{H}$, em 3.614, 3.557, 3.533 e $3.417 \mathrm{~cm}^{-1}$. Nos espectros de IV obtidos para as amostras calcinadas (Figuras 2b, 2c e 2d), essas bandas não são mais observadas evidenciando o desordenamento, ou mesmo a destruição, da estrutura cristalina da glauconita.
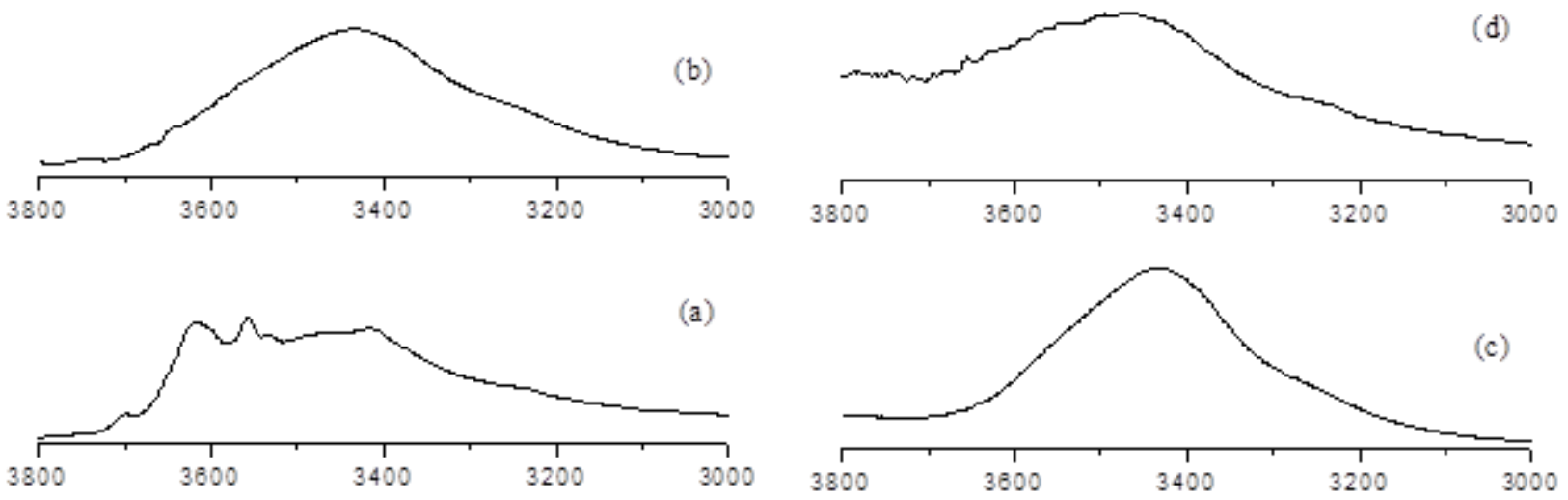

Comprimento de Onda $\left(\mathrm{cm}^{-1}\right)$

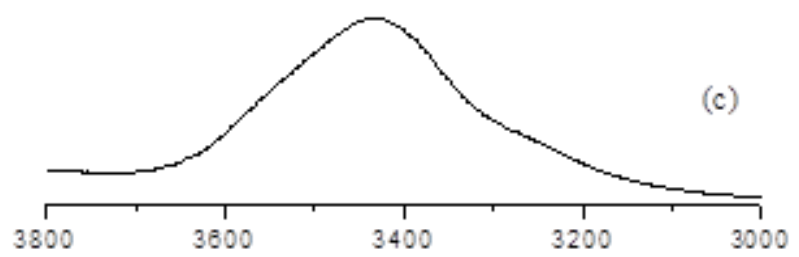

Comprimento de Onda $\left(\mathrm{cm}^{-1}\right)$

Figura 2 - Espectro obtido na região do infravermelho para a amostra de verdete (a) in natura, (b) calcinada a $800^{\circ} \mathrm{C}$, (c) $1.000^{\circ} \mathrm{C}$ e (d) $1.200^{\circ} \mathrm{C}$ na região de 3.800 a $3.000 \mathrm{~cm}^{-1}$.

A estrutura do silicato é caracterizada pela existência de bandas ao redor de $1013 \mathrm{~cm}^{-1}$ que são atribuídas aos modos de vibração de estiramento das ligações Si-O-Si no espectro de IV da 
amostra original de verdete de Cedro do Abaeté (Tabela 3). Quando as amostras são calcinadas, observa-se o deslocamento dessa banda para comprimentos de onda maiores. Sabe-se que para materiais amorfos com elevado conteúdo de sílica, normalmente pode-se observar em espectros no infravermelho o aparecimento de bandas referentes à vibração de estiramento das ligações do grupamento $\mathrm{SiO}_{4}$, em aproximadamente $1.100 \mathrm{~cm}^{-1}$. Dessa forma, o deslocamento das bandas nos espectros de IV das amostras calcinadas, em relação à banda original da amostra de verdete de Cedro do Abaeté in natura, pode evidenciar a formação da rede vítrea nas amostras calcinadas à medida que a temperatura de calcinação aumenta. Assim, pode-se afirmar, com base nos espectros obtidos, que quando a amostra é calcinada a $800^{\circ} \mathrm{C}$ há apenas uma diminuição no ordenamento do material, o que provoca uma maior solubilidade dos íons potássio. Com o aumento da temperatura de calcinação da amostra, observa-se a diminuição no teor de potássio extraído, pois ocorre uma grande variação na estrutura do material, observando-se a formação de uma fase amorfa, rica em sílica, de baixa solubilidade. Dessa forma, os íons potássio ficam ainda mais retidos na estrutura do material diminuindo sua solubilidade.

Tabela 3 - Bandas relativas ao estiramento das ligações Si-O-Si no espectro de IV para as amostras de verdete de Cedro do Abaeté in natura e calcinadas.

\begin{tabular}{c|c}
\hline AMOSTRA & $\begin{array}{c}\text { BANDA OBSERVADA RELATIVA AO ESTIRAMENTO } \\
\text { DE Si-O-Si }\left(\mathrm{cm}^{-1}\right)\end{array}$ \\
\hline VERDETE IN NATURA & 1013 \\
\hline VERDETE CALCINADO A $800^{\circ} \mathrm{C}$ & 1038 \\
\hline VERDETE CALCINADO A $1000^{\circ} \mathrm{C}$ & 1050 \\
\hline VERDETE CALCINADO A $1200^{\circ} \mathrm{C}$ & 1080 \\
\hline
\end{tabular}

Na Figura 4 constam os difratogramas de raios $X$ para as amostras calcinadas de verdete, cuja análise dos resultados indica que a amostra calcinada a $800^{\circ} \mathrm{C}$ (Figura 4 (a)) ainda apresenta pico relativo ao mineral glauconita. À medida que a temperatura de calcinação aumenta há o desaparecimento do pico relativo a esse mineral. Nota-se ainda a formação de uma nova fase mineral, o espinélio, e também surgimento de halo amorfo (abaulamento da linha base do difratograma) que confirma a formação de material vítreo evidenciado anteriormente pelos resultados de infravermelho. Na amostra calcinada a $800^{\circ} \mathrm{C}$ não houve formação de material vítreo uma vez que não há halo amorfo no difratograma dessa amostra (Figura 4a). Sabe-se que a fase amorfa, rica em sílica, é de baixa solubilidade. Sendo assim, os íons potássio ficariam retidos nessa rede e sua solubilidade diminuiria. Portanto, pode-se relacionar o aumento na solubilidade do potássio nessa amostra com o desordenamento da estrutura cristalina da glauconita, sendo que não ocorre a formação de fase vítrea. As amostras calcinadas a 1.000 e $1.200^{\circ} \mathrm{C}$ possuem baixa solubilidade em relação ao nutriente potássio. Pode-se relacionar essa diminuição com a formação de material vítreo nas amostras, evidenciada pelos resultados advindos das técnicas de DRX e IV. 


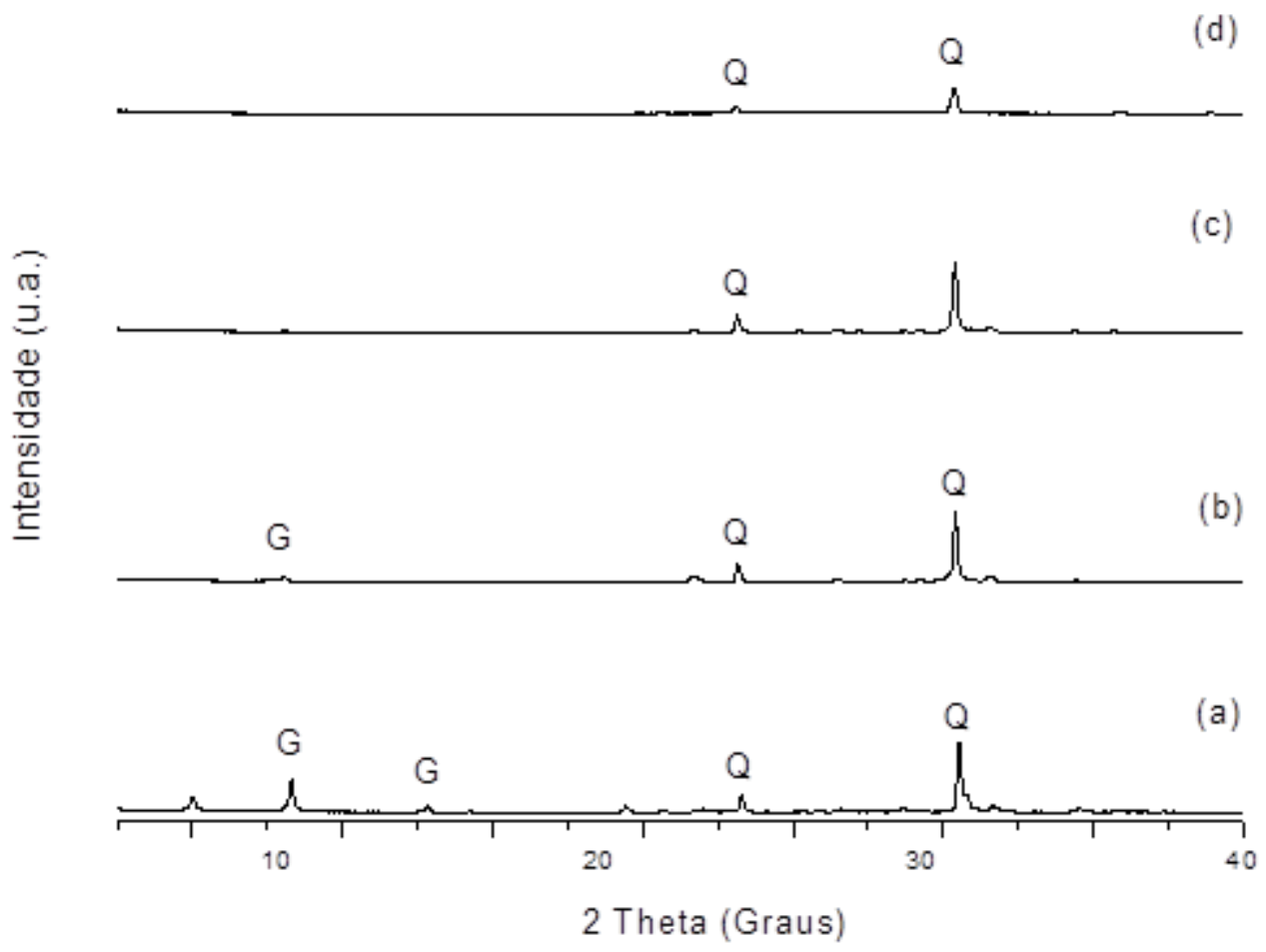

Figura 4 - Difratograma de raios $X$ para a amostra de verdete in natura (a) calcinada a $800^{\circ} \mathrm{C}$ (b), $1.000^{\circ} \mathrm{C}$ (c) e $1.200^{\circ} \mathrm{C}$ (d). ( $\mathrm{G}=$ Galuconita e $\mathrm{Q}=$ Quartzo)

\section{CONCLUSÃO}

O verdete de Cedro do Abaeté in natura, ou seja, sem nenhum tipo de tratamento, possui baixa solubilidade do nutriente potássio. Somente $0,4 \%$ do teor total desse nutriente estão na forma solúvel. Quando a rocha é calcinada a $800^{\circ} \mathrm{C}$, a solubilidade dos íons potássios aumenta em mais de seis vezes. Entretanto, quando calcinada a 1.000 e $1.200^{\circ} \mathrm{C}$ esse teor diminui para 0,5 e $0,06 \%$, do $\mathrm{K}$ total, respectivamente. Portanto, o verdete de Cedro do Abaeté possui potencial para ser utilizado como fertilizante alternativo, quando tratado termicamente a $800^{\circ} \mathrm{C}$.

\section{REFERÊNCIAS}

1. CHESHIRE, M.C., BISH, D.L. Mineralogical and sulphur isotopic evidence for the influence of sulphate-reducing and -disproportionating bacteria on pyrite and marcasite formation in the Georgia kaolins. Clay Minerals, v. 47, p. 559-572, 2012.

2. DANA, J.D. Mineralogia descritiva: Silicatos. In.: Manual de Mineralogia. Rio de Janeiro, p. 423$564,1978$.

3. DUARTE, I.N., PEREIRA, H.S., KORNDÖRFER, G.H. Lixiviação de potássio proveniente do termopotássio. Pesq. Agropec. Trop., Goiânia, v. 43, n. 2, p. 195-200, 2013.

4. KOSTER, H.M. Determination of the chemical structural formula of 2:1 layer silicates based on the measurement of the interlayer charge and cation exchange capacities. Clay Minerals, v. 12, p. 45-54, 1977.

5. MARTINS, V., GONÇALVES, A.S.F., MARCHI, G., GUILHERME, L.R.G., MARTINS, E.S. 
Solubilização de potássio em misturas de verdete e calcário tratadas termoquimicamente. Pesq. Agropec. Trop., Goiânia, v. 45, n. 1, p. 66-72, 2015.

6. MANCUSO, M.A.C., SORATTO, R.P., CRUSCIOL, C.A.C., CASTRO, G.S.A. Effect of potassium sources and rates on arabica coffee yield, nutrition, and macronutrient export. R. Bras. Ci. Solo, v. 38, p. 1448-1456, 2014

7. OLIVEIRA, L.A.M. Potássio. In: LIMA, T. M.; NEVES, C. A. R. (Eds.). Sumário Mineral. Brasília: DNPM, 2014. p. 100-101.

8. OSPITALI, F., BERSANI, D., Di LEONARDO, G., LOTTICI, P.P. Green earths: vibrational and elemental characterization of glauconites, celadonites in historical pigments. Journal of Raman Spectroscopy, v. 39, p. 1066-1073, 2008.

9. PESSOA, R.S., SILVA, C.A., MORETTI, B.S., FURTINI NETO, A.E., INDA, A.V., CURI, N. Solubilization of potassium from alternative rocks by humic and citric acids and coffee husk. Ciênc. Agrotec., Lavras, v. 39, n. 6, p. 553-564, 2015.

10. SANTOS, W.O., MATTIELLO, E.M., DA COSTA, L.M., ABRAHÃO, W.A.P. Characterization of verdete rock as a potential source of potassium. Rev. Ceres, Viçosa, v. 62, n.4, p. 392-400, 2015.

11. SILVA, A.A., LANA, R.M.Q. Incubação do Verdete com Diferentes Fontes de Ácidos para Disponibilização de Potássio, Cálcio, Magnésio do Solo. Holos, Ano 31, Vol 5, p. 73-83, 2015.

12. SILVA, A.A.S. Caracterização de Flogopitito da Bahia para Uso como Fertilizante Alternativo de Potássio. Dissertação de Mestrado. Universidade Federal do Rio de Janeiro, 90p., 2009.

13. SILVA, A.A.S., SAMPAIO, J.A., GARRIDO, F.M.S., MEDEIROS, M.E., BERTOLINO, L.C. Characterization of a Greensand Slate from Cedro do Abaeté - Brazil to the Synthesis of a Potassium Thermophosphate. In.: EPD Congress 2011. Sergio N. Monteiro; Prince N. Anyalebechi; Dirk E. Verhulst; Joseph A. Pomykala (Editors), San Diego, v. 1, p. 38-45, 2011.

14. SILVA, A.A.S., MEDEIROS, M.E., SAMPAIO, J.A., GARRIDO, F.M.S. Verdete de Cedro do Abaeté como fonte de potássio: Caracterização, tratamento térmico e reações com CaO. Matéria, Rio, v. 17, n. 3, p. 1061-1073, 2012a.

15. SILVA, A.A.S., MEDEIROS, M.E., SAMPAIO, J.A., GARRIDO, F.M.S. Caracterização do verdete de Cedro do Abaeté para o desenvolvimento de um material com liberação controlada de potássio. Holos, Ano 28, Vol 5, p. 42-51, 2012b.

16. SRASRA, E., TRABELSI-AYEDI, M. Textural properties of acid activated glauconite. Applied Clay Science, v. 17, p. 71-84, 2000.

17. TEIXEIRA, A. M. S.; SAMPAIO, J. A.; GARRIDO, F. M. S.; MEDEIROS, M. E. Technological characterization of phonolite rock to be applied as a source of nutrients to the Brazilian agriculture. In: MONTEIRO, S. N. et al. (Eds.). . EPD Congress 2011. San Diego: John Wiley \& Sons, Inc., p. 81-86, 2011.

18. TEIXEIRA, A. M. S.; SAMPAIO, J. A.; GARRIDO, F. M. S.; MEDEIROS, M. E. Avaliação da rocha fonolito como fertilizante alternativo de potássio. Holos, Ano 28, Vol 5, p. 21-33, 2012a.

19. TEIXEIRA, A. M. S.; GARRIDO, F. M. S.; MEDEIROS, M. E.; SAMPAIO, J. A. Caracterização e classificação quanto ao risco ambiental do estéril da mina de cromita do município de Andorinha, Bahia. Química Nova, v. 35, n. 9, p. 1794-1799, 2012b. 
20. TEIXEIRA, A. M. S.; GARRIDO, F. M. S.; MEDEIROS, M. E.; SAMPAIO, J. A. Estudo do comportamento térmico da rocha fonolito com fins à produção de fertilizantes. Holos, Ano 31, Vol 5, p. 52-64, 2015a.

21. TEIXEIRA, A. M. S.; GARRIDO, F. M. S.; MEDEIROS, M. E.; SAMPAIO, J. A. Effect of thermal treatments on the potassium and sodium availability in phonolite rock powder. International Journal of Mineral Processing, v. 145, p. 57-65, 2015b.

22. TOLEDO PIZA, P.A., BERTOLINO, L.C., SILVA, A.A.S., SAMPAIO, J.A., LUZ, A.B. Verdete da região de Cedro do Abaeté (MG) como fonte alternativa para potássio. Geociências, São Paulo, UNESP, v.30, p. 345-356, 2011.

23. VALLARELI. J.V. Ardósias Verdete de Cedro do Abaeté na Produção de Termofosfato Potássico Fundido e sua Eficiência Agronômica. Anais da Academia Brasileira de Ciências, v. 31, p. 363375, 1993. 